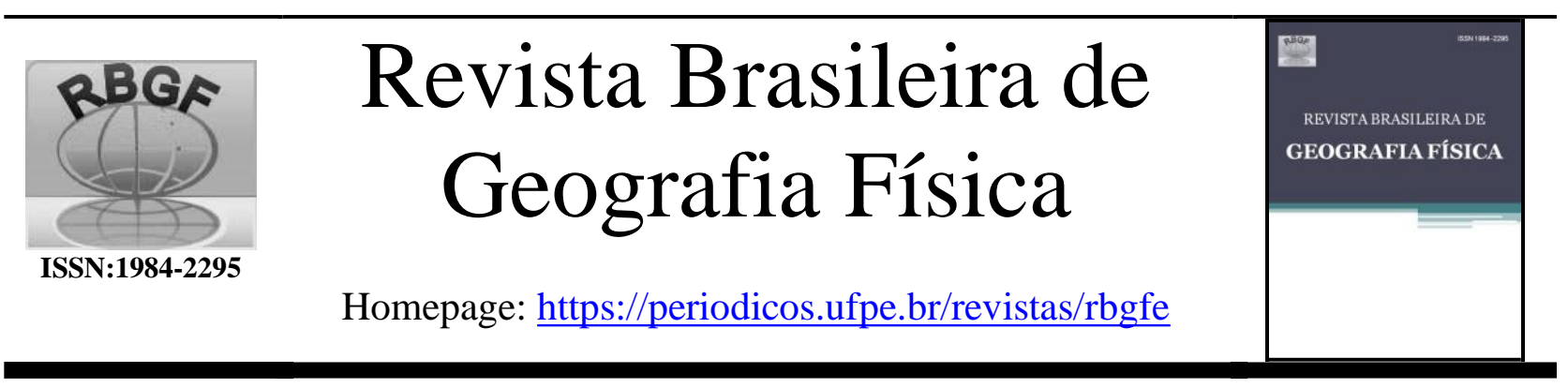

\title{
Análise Descritiva da Precipitação, Temperatura, Umidade e Tendências Climáticas no Recife - PE
}

\author{
Roni Valter de Souza Guedes'; Thiago Luiz do Vale Silva²
}

\begin{abstract}
${ }^{1}$ Dr. em Meteorologia, Analista em Gestão de Recursos Hídricos e Climáticos, Agência Pernambucana de Águas e Clima, Avenida Cruz Cabugá, 1111, Santo Amaro, CEP: 50040-000, Recife, Pernambuco. roniguedes84@yahoo.com.br (autor correspondente); ${ }^{2}$ Dr. em Oceanografia, Analista em Gestão de Recursos Hídricos e Climáticos, Agência Pernambucana de Águas e Clima, Avenida Cruz Cabugá, 1111, Santo Amaro, CEP: 50040-000, Recife, Pernambuco. thiago.vale@apac.pe.gov.br
\end{abstract}

Artigo recebido em 12/06/2020 e aceito em 03/09/2020

\section{R E S U M O}

O objetivo deste estudo é descrever e avaliar as mudanças e tendência das variáveis meteorológicas no Recife - PE durante o período de 1961 a 2019, bem como verificar indicações de mudanças climáticas sobre a Região. A metodologia engloba uma análise exploratória e descritiva com distribuição de frequencia por faixas de intensidades pluviométricas e identificação de tendências em escalas temporais da precipitação, temperaturas e umidade do ar. Os resultados apontaram para redução das precipitações em algumas faixas intermediárias de 10 a 70 mm e aumento na quantidade de dias sem chuva, nas chuvas abaixo de $10 \mathrm{~mm}$ e chuvas com intensidade acima de $100 \mathrm{~mm}$, porém, com tendência no acumulado anual da precipitação de redução nas últimas décadas. Observou-se de forma evidente tendências de aumento das temperaturas máximas, mínimas e diminuição das umidades relativa do ar, com taxas diferenciadas entre os meses secos e chuvosos, e destaque para maiores variações nas estações de transição e indicativo de verões mais quentes e secos, ainda foi identificado comportamento divergente da temperatura mínima se estabilizando durante a quadra chuvosa, e redução na última década. Devido a isto, a temperatura máxima teve aquecimento maior de $0.23^{\circ} \mathrm{C} /$ década, enquanto a mínima está subindo $0.13^{\circ} \mathrm{C} /$ década e a umidade relativa caindo $0.53 \% /$ década. As transformações no clima do Recife registraram comportamentos diferentes em escalas sazonais e uma alteração dos padrões climatológicos, com aumento da concentração de chuvas extremas na quadra chuvosa, diminuição das chuvas nos períodos mais secos e aumento na probabilidade da ocorrência das ondas de calor.

Palavras -chave: Mudança do Clima, frequências de intensidade, variações sazonais e decadais

\section{Descriptive Analysis of Precipitation, Temperature, Humidity and Climate Trends in Recife - PE}

\begin{abstract}
A B S T R A C T
This study aims to describe and evaluate the changes and trends of meteorological variables in Recife - PE during the period from 1961 to 2019 and verify indications of climatic changes over the Region. The methodology includes an exploratory and descriptive analysis with frequency distribution by ranges of rainfall intensity and identifying trends in temporal scales of precipitation, temperatures, and air humidity. The results pointed a precipitation reduction in ranges between 10 to $70 \mathrm{~mm}$, an increase in the number of days without rain, in rains below $10 \mathrm{~mm}$, and rains with intensity above $100 \mathrm{~mm}$, however, with a trend in the annual accumulated rainfall reduction in recent decades. There was an evident trend towards increasing maximum and minimum temperatures and decreasing relative humidity in the air, with different rates between the dry and rainy months, with emphasis on more significant variations in the transition seasons and indicative of hotter and drier summers, divergent behavior of the minimum temperature, stabilizing during the rainy season, and reduction in the last decade. Thus, the rate of increasing maximum temperature is more than $0.23^{\circ} \mathrm{C} / \mathrm{decade}$, while the minimum temperature is rising $0.13^{\circ} \mathrm{C} /$ decade, and the relative humidity is decreasing at a rate of $0.53 \% /$ decade. The local climate change at Recife registered different behaviors on seasonal scales and diversity in
\end{abstract}


climatological patterns, with an increase in the concentration of extreme rainfall in the rainy season, a decrease in rainfall in the driest periods. Also, an increase in the probability of the occurrence of heatwaves.

Keywords: Climate change, intensity frequencies, seasonal and decadal variations

\section{Introdução}

O Nordeste Brasileiro (NEB) apresenta uma variabilidade climática espaço temporal pronunciada devido às diversas forçantes atmosféricas (Hänsel et al., 2016; Hastenrath, 2012; Rao et al., 1993). As variabilidades de chuva nas áreas norte e central nordestina estão associados à migração norte e sul da Zona de Convergência Intertropical (ZCIT) (Hastenrath, 2012; Marengo et al., 2017; Moscati e Gan, 2007; Rodrigues et al., 2011). Nas partes sul, oeste e central do NEB a Zona de Convergência do Atlântico Sul (ZCAS) contribuem bastante com as chuvas na região durante a primavera e verão austral (Paegle e Mo, 2002). Nos meses de janeiro e fevereiro, existe a ocorrência dos Vórtices Ciclônicos de Altos Níveis (VCAN) (Fereira e Melo, 2005). No leste do Nordeste as precipitações são moduladas pelos distúrbios ondulatórios de leste (Gomes et al., 2015; Kouadio et al., 2012; Ramos, 1975; Torres e Ferreira, 2011) com maior precipitação entre os meses de maio e julho, e média anual acima dos $1500 \mathrm{~mm}$.

Desde o período colonial, no século XVI, o NEB registra êxodos rurais das regiões semiáridas para áreas costeiras devido ao sucessivo eventos de secas severas (Marengo et al., 2017). Enquanto isto, nas áreas costeiras do Norte e Leste do Nordeste (NNEB e ENEB), eventos de chuvas severas precedem eventos de enchentes, inundações, alagamentos e deslizamento de massa, causando perdas econômicas e sociais, principalmente nas partes menos abastadas financeiramente, que estão presentes em locais adversos, como córregos, vales, encostas e morros (Gomes et al. 2012, Hounsou-gbo et al. 2015). De acordo com Silva (2020) nas últimas décadas os eventos extremos tem ganhado destaques devidos os impactos socioambientais nas grandes áreas urbanas de inúmeras cidades do Brasil.

As Temperaturas da Superfície do Mar (TSM) sobre as regiões tropicais do Atlântico Sul (ATS) e as condições do El Niño de Oscilação Sul (ENSO) interagem de forma global com a circulação geral da atmosfera, causando impactos diretos e contundentes sobre a variabilidade de chuvas e temperatura sobre a região do NEB, e provocam alterações dos seus padrões sistematicamente (Andreoli e Kayano, 2006, 2007; Aragão, 1998; Moura e Shukla, 1981; SILVA et al., 2018; Silva e Guedes, 2012). Portanto, os efeitos de mudanças climáticas sobre os oceanos Pacífico e Atlântico devem alterar padrões intrasazonais de diversas regiões do globo por meio das teleconexões (Michel et al., 2020), o que deve ocorrer também no NEB, devido a alta variabilidade climática em relação aos oceanos tropicais.

Considerando as mazelas sociais associadas com habitação, desigualdade financeira e uma forte dependência com o clima local, o Nordeste do Brasil passa a ser um local com grande vulnerabilidade social devido aos efeitos das mudanças e variabilidades climáticas (Hastenrath, 2012). Espera-se que as mudanças climáticas estejam influenciando diretamente no modo de vida da população do NEB em especial a do ENEB, desde as mudanças visuais da linha de costa, avanço do mar (Costa et al., 2010), das consequências sócio-econômicas como interdição das avenidas devido aos frequentes alagamentos (Hastenrath, 2012) e até mesmo nas associações com vetores de doenças, como o surto de Dengue, Zika e Chikugunya (Ebi e Nealon, 2016), problemas que influenciam no aumento das vulnerabilidades sociais, causando mais desigualdade social e maior impacto na sociedade do NEB.

As variabilidades do clima em Pernambuco necessitam ser bem estudadas para que haja uma viabilidade preditiva no intuito de mitigar efeitos dos eventos extremos. A prefeitura do Recife em 2019 preparou um documento que mostra a susceptibilidade da Região às mudanças do clima e prioriza ações para mitigação das vulnerabilidades que a cidade enfrenta e deve enfrentar (Prefeitura Municipal do Recife, 2019). Segundo (Debortoli et al., 2017), a região leste do NEB possui um cenário de aumento da vulnerabilidade climática nos cenários de mudanças climáticas. Assim, o Recife pela sua posição geográfica centralizada na faixa leste, sua importância regional e desenvolvimento estrutural e populacional acentuado pode ser representativa do comportamento climático desta região.

O município do Recife possui desigualdades 
sociais visíveis em seu território, sendo regiões planas com alto valor imobiliário e setores do subúrbio com habitações em relevo acidentado, morros e encostas, propícios a deslizamentos de massas devido a instabilidade geológica, geralmente na Zona Norte (Gomes et al., 2012). O Recife apresenta totais mensais impactados pelas chuvas intensas que geram um histórico de problemas agravados pela grande quantidade de rios, córregos e afluentes. Segundo Wanderley (2018), as chuvas diárias no Recife possui um tempo de retorno de dois anos para eventos de $112.7 \mathrm{~mm}$, cinco anos para $151.9 \mathrm{~mm}$. Ainda segundo Wanderley (2018), em comparação com o tempo de retorno de outras regiões afirmaram que Recife tem uma alta recorrência de volumes máximos de precipitação.. Ainda, apresenta indicativos que chuvas acima de $55 \mathrm{~mm}$ no Recife sempre provocam alagamentos, escorregamentos e outros danos à população (Souza e Azevedo, 2012).

Como se sabe, a sensação térmica está relacionada aos índices de temperatura e umidade e os diversos relatórios do IPCC apontam para um aumento de temperatura no globo, e as projeções para o Brasil indicam crescimento de até $4^{\circ} \mathrm{C}$ até 2100 dependendo das taxas de emissão de poluentes (Marengo, 2007). Souza e Azevedo (2009) identificaram a ocorrência de noites mais quentes e associaram isto à urbanização desenfreada em Recife. E posteriormente que a temperatura máxima também apresenta uma pequena tendência de aumento (Souza e Azevedo, 2012).

Diante do exposto acima, o presente estudo das variações do clima pretende quantificar essas alterações sistemáticas e detalhar um conjunto de dados das variáveis climáticas para municiar os diversos setores da sociedade sobre a evolução em curso e assim poderem inferir os impactos em diferentes áreas. Conhecer o efeito das mudanças climáticas em diferentes em escalas temporais são imprescindíveis no planejamento estratégico e na tomada de decisões. Devido a isto, o presente estudo separa as tendências em escalas mensais, sazonais e no período chuvoso e seco, bem como diferenciar faixas de intensidades pluviométricas a fim de quantificar as tendências de precipitação com maior detalhamento. Assim, o objetivo deste trabalho é de analisar a frequência, distribuição e tendências das diferentes intensidades de precipitação, das temperaturas máximas e mínimas e da umidade relativa do ar na cidade do Recife para comprovar as alterações no padrão do clima.

\section{Material e métodos}

\section{Área de Estudo}

A área em análise compõe o município do Recife, localizada no litoral do estado de Pernambuco, setor oriental da região Nordeste do Brasil (Figura 1). Recife é a capital estadual, possui um PIB acima dos 30 Bilhões correspondente a $31,5 \%$ do Estado, com uma população estimada de 1.645.727 habitantes, e possui uma densidade popupacional superior a $7.040 \mathrm{hab} / \mathrm{km}^{2}$ (IBGE, 2019). A região metropolitana do Recife compõe a maior área urbana do Estado com mais de 4 milhões de habitantes, e praticamente não há uma separação urbana entre os limites do Recife com os municípios de Olinda, Paulista, Camaragibe, São Lourenço da Mata e Jaboatão dos Guararapes.

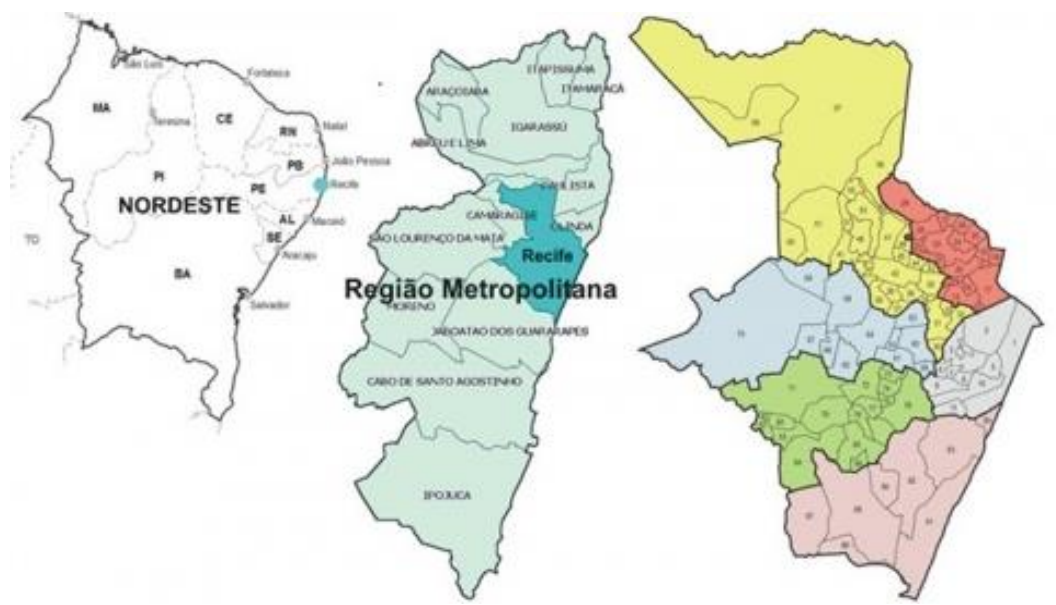

Figura 1 - Localização da área em estudo. Fonte: Prefeitura municipal do Recife (2020). 


\section{Dados Observados}

Neste trabalho foram observados dados de precipitação de diferentes postos da APAC, e utilizados para análise dados diários do período de 1961 a 2019 das variáveis temperaturas máximas e mínimas, umidade relativa do ar e precipitações da estação convencional do INMET, localizada em -34,96 W e -8,06 S, e altitude de 11,3 m. A metodologia para descrever o comportamento das variáveis utilizou distribuição de frequência por faixa de intensidade e escalas temporais decadais, anuais, quadra chuvosa, mensais e climatológicas. Também se baseou na densidade de probabilidade para análises específicas.

Os dados foram organizados e separados por dia. Os dados de precipitação são registrado em um intervalo de $24 \mathrm{~h}$ sendo coletado todos os dias as $09 \mathrm{~h}$ da manhã. Os dados de temperatura e umidade são coletados por estações convencionais ao menos três vezes ao dia nos horários sinóticos das 00, 06, 12 e 18 UTC. Os dados aqui utilizados foram provindos do Instituto Nacional de Meteorologia - INMET.

Para identificar mudanças nos padrões de chuva, foram feitas classificações específicas do comportamento pluviométrico. As categorias de chuva disposta na Tabela 1, reflete as precipitações classificadas baseadas nos danos que podem se originar, e de um conjunto de prédefinições de artigos anteriores, bem como classificações do operacional do serviço de meteorologia de Pernambuco - APAC.

\section{Análises Descritivas}

A organização e operação dos dados foram feitos com software de cálculo científico Matlab $^{\circledR}$ (Os scripts podem ser solicitados via email do autor). Devido ao uso dos dados diários, separou-se em dias, meses, quadra chuvosa e estações do ano. Cada uma variável organizada foram transformada em séries temporais.

Cada série temporal possui uma relação com máximos e mínimos de temperatura, umidade média, na escala mensal, sazonal e quadra chuvosa. Com isso foi retirado tendências do comportamento climático nas diferentes escalas temporais, bem como sua tendência com o passar do ano.

Foram realizados, uma separação nos intervalos climatológicos, sendo realizados gráficos de função densidade de probabilidade com as temperaturas máximas e mínimas dos períodos de 30 anos, compreendidos em 1961 a 1991, 1976 a 2006 e de 1991 a 2019. Com isso mostrou-se o comportamento de mudança em intervalos climáticos diferentes, podendo avaliar um comportamento mais contínuo. As funções densidade de probabilidade mostram os valores de maior probabilidade de ocorrência e os extremos. Com isso pode-se avaliar as mudanças de comportamento provável durante os períodos analisados, permitindo avaliar a probabilidade de ocorrência de ondas de calor na estação medição.

As análises pluviométricas foram separadas por categorias, no intúito de avaliar a intensidade da chuva. Os intervalos são definidos obedecendo critérios operacionais da Agência Pernambucana de Águas e Clima - APAC, tais intervalos são definidos por estudos prévios e utilizado em diversos orgãos de monitoramento.

A organização dos dados se deu pelo acumulado da chuva diária, distribuído em uma matriz de intensidades para cada mês de 1961 a 2019. Com isso se construiu séries temporais com as frequencias de ocorrências de cada categoria e realizado as tendências climáticas de meses, estações, anos e décadas. O período chuvoso foi definido como somatório das ocorrências de maio a julho. Assim pode-se obter a probabilidade de ocorrência em cada nível de precipitação, bem como a tendência de probabilidade de cada categoria de precipitação.

Tabela 1 - Classificação e intervalos escolhidos, bem como a chuva correspondente.

\begin{tabular}{cc}
\hline Categoria & Intervalo $(\mathbf{m m})$ \\
\hline Sem Chuva & $\mathrm{P}<1$ \\
Chuva Leve & $1<\mathrm{P}<10$ \\
Chuva Fraca & $10<\mathrm{P}<30$ \\
Chuva Moderada & $30<\mathrm{P}<50$ \\
Chuva Forte & $50<\mathrm{P}<70$ \\
Chuva muito Forte & $70<\mathrm{P}<100$ \\
Chuva Extrema & $\mathrm{P}>100$ \\
\hline
\end{tabular}




\section{Resultados e discussão Dados Pluviométricos}

A Figura 2 mostra a quantidade de casos de chuvas com valores acima de $100 \mathrm{~mm}$ em Recife do período de 1931 a 2019. As cores variadas mostram os bairros em que as medições foram feitas. A dificuldade em encontrar dados com longos períodos de medição com o mínimo de falha, mostra a necessidade de uma política Estadual que seja eficaz na qualidade dos dados medidos. O histórico de pluviometria no Recife reflete o que ocorre em todo o Estado, havendo a necessidade de manter uma rede mínima, em que sejam imutáveis e intransferíveis, gerando dados confiáveis e bem estruturados para estudos climáticos.

O conjunto de dados na Figura 2 mostra como o histórico de dados de precipitação em Recife, são variados e possuem falhas de medição em todas as séries, com ausência de medições contínuas, ativação e desativação aleatória de postos, além de mudanças nas localizações e posição dos pluviômetros. Estas variantes exigem a necessidade do uso de ferramentas matemáticas para reconstrução das séries, principalmente para estudos climáticos, interferindo na qualidade e distribuição dos dados meteorológicos medidos.

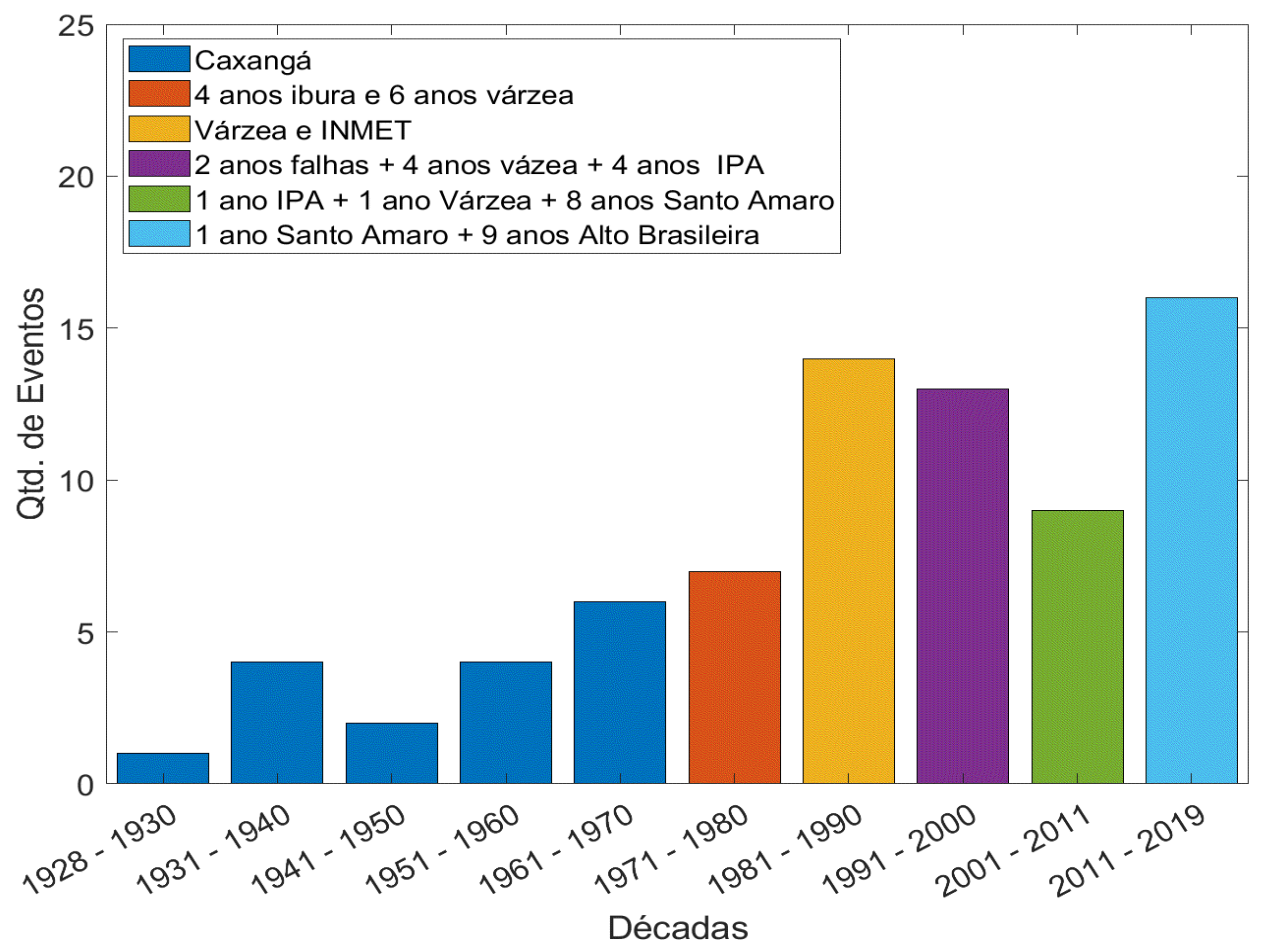

Figura 2 - Distribuição decadal de casos acima de 100mm para estações pluviométricas em diferentes bairros e períodos.

O município do Recife, por ser a capital do Estado, ainda dispões de várias opções para compor sua série, diferente de outras localidades que detém menos postos e por isso são mais afetadas pela ausência de uma rede mínima permanente. Mostra-se, portanto, a necessidade de uma política de Estado que seja eficaz e rígida no quesito de manter uma rede de dados meteorológicos permanente ao longo do tempo, para que os dados tenham qualidades $\mathrm{e}$ representem historicamente as chuvas das regiões onde estão localizadas.
Dentre o conjunto citado de postos do Recife, os três principais são Caxangá (1931 a 1970), Várzea (1967 a 2020) e Alto da Brasileira (1996 a 2020), todos apresentam falhas de medições contínuas de escalas mensais e anuais e não existindo dados para o período de 1986 a 1992 em nenhum dos postos monitorados pela atual agência meteorológica do Estado (APAC, criada em meados de 2010). Por isto, resolveu-se analisar os dados de uma estação convencional pertencente ao INMET por apresentar maior 
consistência de longo prazo e excluir a necessidade de reconstrução estatística da série.

\section{Climatologia de chuvas no Recife}

A Figura 3 indica a densidade mensal acumulada das faixas de intensidade da precipitação. Observa-se a maior concentração de dias nas faixas de precipitação leve $(1<\mathrm{P}<10$ $\mathrm{mm})$, e acrescentando as chuvas fracas, comprova-se que a característica de chuvas do Recife é de acumulados entre $1 \mathrm{~mm}$ e $30 \mathrm{~mm}$, e ocupa mais de $90 \%$ dos dias na maioria dos meses.

As faixas com precipitações moderadas a extrema (acima de $30 \mathrm{~mm}$ ) ficam mais

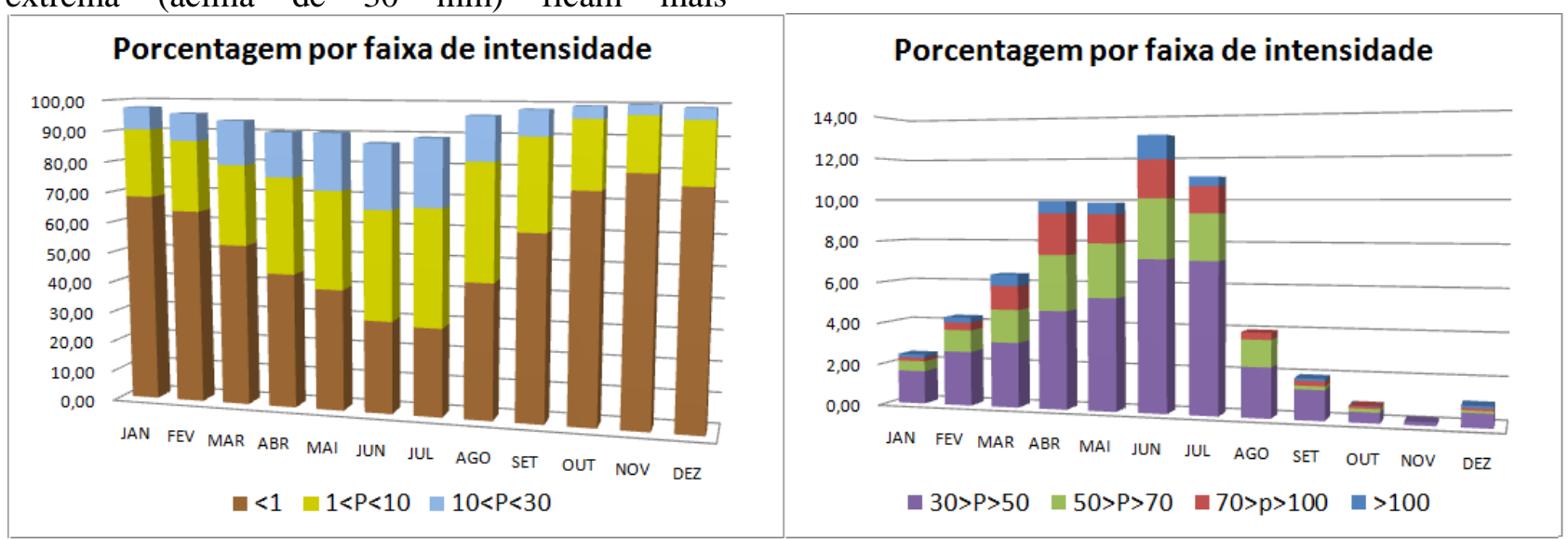

Figura 3 - Densidade mensal da precipitação por faixa de intensidade no Recife.

Um detalhamento da distribuição da intensidade das precipitações em cada mês do ano disponibilizado na Tabela 2 mostra Recife com uma média de 55\% dos dias sem chuva $(\mathrm{P}<1$ $\mathrm{mm}$ ), sendo os meses mais secos (OND) possuindo mais de $70 \%$ dos dias sem chuva e os concentradas entre o outono e inverno, o que caracteriza dois períodos bem definidos quanto ao risco para ocorrência de eventos intensos de precipitação.

Este comportamento está ligado diretamente com a qualidade do período chuvoso, em que o outono e inverno representam os maiores volumes de chuva para Região. Dos eventos meteorológicos atuantes durante este período, a Zona de Convergência Intertropical atua no inicio do outono, entre março e abril (Marengo et al., 2017; Silva e Guedes, 2012), enquanto que os Distúrbios Ondulatórios de Leste, predominam nas duas estações (Gomes et al., 2015; Silva et al., 2018).

Tabela 2. Porcentagem de ocorrência mensal da precipitação por faixa de intensidade da precipitação (mm).

\begin{tabular}{cccccccc}
\hline \multicolumn{7}{c}{ PORCENTAGEM DAS FAIXAS DE CHUVA EM CADA MÊS } \\
\hline INTENSIDADE & $\mathbf{P}<\mathbf{1}$ & $\mathbf{1}<\mathbf{P} \leq \mathbf{1 0}$ & $\mathbf{1 0}<\mathbf{P} \leq \mathbf{3 0}$ & $\mathbf{3 0}<\mathbf{P} \leq \mathbf{5 0}$ & $\mathbf{5 0}<\mathbf{P} \leq \mathbf{7 0}$ & $\mathbf{7 0}<\mathbf{P} \leq \mathbf{1 0 0}$ & $\mathbf{P}>\mathbf{1 0 0}$ \\
JAN & 68,20 & 22,19 & 7,19 & 1,59 & 0,49 & 0,16 & 0,16 \\
FEV & 63,72 & 23,15 & 8,84 & 2,61 & 1,06 & 0,37 & 0,25 \\
MAR & 53,02 & 26,26 & 14,31 & 3,13 & 1,59 & 1,15 & 0,55 \\
ABR & 44,19 & 31,48 & 14,41 & 4,71 & 2,67 & 1,99 & 0,57 \\
MAI & 39,80 & 31,96 & 18,37 & 5,37 & 2,58 & 1,37 & 0,55 \\
JUN & 30,30 & 35,78 & 20,92 & 7,24 & 2,83 & 1,81 & 1,13 \\
JUL & 28,93 & 38,25 & 21,75 & 7,18 & 2,19 & 1,26 & 0,44 \\
AGO & 44,22 & 37,81 & 14,03 & 2,36 & 1,26 & 0,33 & 0,00 \\
SET & 60,45 & 29,49 & 8,14 & 1,41 & 0,17 & 0,23 & 0,11 \\
OUT & 73,86 & 21,64 & 3,73 & 0,49 & 0,16 & 0,11 & 0,00 \\
NOV & 79,53 & 17,22 & 3,08 & 0,17 & 0,00 & 0,00 & 0,00 \\
DEZ & 75,90 & 19,66 & 3,45 & 0,66 & 0,11 & 0,11 & 0,11 \\
\hline
\end{tabular}


$\mathrm{Na}$ medida que se considera acumulados maiores $\mathrm{P}>10 \mathrm{~mm}$ é observada uma taxa de aumento acentuada positiva de janeiro a julho, com queda brusca a partir de agosto. A evolução mês a mês das frequências para cada faixa de intensidade é observada na Tabela 2. A faixa de chuva fraca $(10<\mathrm{P}<30 \mathrm{~mm})$ apresenta evolução da frequência de $7 \%$ em janeiro até o máximo de $21,7 \%$ em julho, reduzindo nos meses seguintes. Com isto essa intensidade ocorre com média anual de $11,5 \%$ dos dias, sendo na quadra chuvosa $18,9 \%$.

As faixas maiores de precipitações $\mathrm{P}>30$ $\mathrm{mm}$ apresentam uma frequência relativa mais baixa, sendo o mês de junho com maior ocorrência $13 \%$, e os últimos meses do ano com frequência quase nula. Por isto, destacando apenas a média da quadra chuvosa de abril a julho, a categoria de chuva moderada $(30<\mathrm{P}<50 \mathrm{~mm})$ tem frequência de $6 \%$; chuva forte $(50<\mathrm{P}<70$ $\mathrm{mm})$ tem ocorrência em 2,6\% dos dias; chuva muito forte $(70<\mathrm{P}<100 \mathrm{~mm})$ com 1,6\%; e para chuva extrema $(P>100 \mathrm{~mm})$ a frequência é $0,67 \%$.

Nos resultados obtidos por Silva et al., (2020) a partir do standardized precipitation index (SPI) mensal, identificaram que os desvios negativos de chuva ocorrem $38,42 \%$ dos meses, mas apenas em $0,31 \%$ esse déficit atinge a categoria de seca extrema, enquanto que os desvios mensais positivos de precipitação são $27,32 \%$, porém, com a categoria de chuva severa ou extrema em 4,32\% dos casos. Esse resultado corrobora com os resultados encontrados, uma vez que a maior frequência de chuvas entre as categorias de 1 até $30 \mathrm{~mm}$ contribuem para evitar déficits acentuados e por isto secas severas ou extremas são raras em Recife. Em contrapartida, neste trabalho os valores acima de $30 \mathrm{~mm}$ têm uma frequência anual de 5,4\%, e valores acima de $50 \mathrm{~mm}$ no período chuvoso de março a agosto tem uma frequência de 4,04\%. Essas porcentagens bastante próximas justificam os valores de SPI mensal para chuva severa ou extrema encontrados por Silva et al., (2020).

Em termos probabilidade de dias com chuva acumulativa (Tabela 3), observa-se novamente um padrão bem definido em relação aos períodos secos e chuvosos. Verificou-se que os períodos de abril a julho corresponde aos meses com maior concentração de dias com chuva, enquanto que os meses de setembro a janeiro, os de menor dias com chuva. Portanto, os resultados mostram a diferença significativa entre os eventos de chuva em Recife, sendo mais distribuidos nos meses de abril a julho, enquanto que com baixa frequencia de chuva entre setembro a janeiro, independente das intensidades. Observa-se também que a quadra chuvosa apresenta uma média de pelo menos 3 dias por mês com chuvas acima de $30 \mathrm{~mm}$, totalizando mais 13 dias no quadrimestre e 20 dias por ano com chuvas acima desse limiar.

Tabela 3. Valores médios de dias com chuva em determinados intervalos de precipitação.

\begin{tabular}{crrrrrr}
\hline \multicolumn{7}{c}{ NÚMERO DE DIAS POR MÊ (EM MÉDIA) } \\
\hline RESUMO & $>\mathbf{1 ~} \mathbf{~ m m}$ & $\mathbf{> 1 0} \mathbf{~ m m}$ & $\mathbf{> 3 0} \mathbf{~ m m}$ & $\mathbf{> 5 0} \mathbf{~ m m}$ & $\mathbf{> 7 0} \mathbf{~ m m}$ & $>\mathbf{1 0 0} \mathbf{~ m m}$ \\
JAN & 9,86 & 2,98 & 0,75 & 0,26 & 0,10 & 0,05 \\
FEV & 11,25 & 4,07 & 1,33 & 0,52 & 0,19 & 0,08 \\
MAR & 14,57 & 6,42 & 1,99 & 1,02 & 0,53 & 0,17 \\
ABR & 17,30 & 7,54 & 3,08 & 1,62 & 0,79 & 0,18 \\
MAI & 18,66 & 8,75 & 3,06 & 1,39 & 0,59 & 0,17 \\
JUN & 21,61 & 10,51 & 4,03 & 1,79 & 0,91 & 0,35 \\
JUL & 22,03 & 10,17 & 3,43 & 1,21 & 0,53 & 0,14 \\
AGO & 17,29 & 5,57 & 1,22 & 0,49 & 0,10 & 0,00 \\
SET & 12,26 & 3,12 & 0,60 & 0,16 & 0,11 & 0,04 \\
OUT & 8,10 & 1,39 & 0,24 & 0,08 & 0,03 & 0,00 \\
NOV & 6,34 & 1,01 & 0,05 & 0,00 & 0,00 & 0,00 \\
DEZ & 7,47 & 1,38 & 0,31 & 0,10 & 0,07 & 0,03 \\
\hline
\end{tabular}

Os valores acima de $50 \mathrm{~mm}$ ocorre em todos os meses do período chuvoso, com uma frequencia de 8 vezes por ano, os valores acima de $70 \mathrm{~mm}$ possui maiores probabilidades de ocorrência 3 vezes por ano, enquanto que valores acima de $100 \mathrm{~mm}$ é mais incerto, sendo a probabilidade de ocorrência próximo a 1 evento anual. Esses resultados conferem com os 
encontrados por Wanderley et al. (2018) que apontaram para chuvas de $50 \mathrm{~mm}$ ocorrendo todo ano e acima de $100 \mathrm{~mm}$ ocorrendo em 41 de 56 anos.

A série histórica analisada apresentou uma média anual de $2269 \mathrm{~mm}$, com maior acumulado mensal em junho com $380 \mathrm{~mm}$ e menor em novembro de $50 \mathrm{~mm}$. A climatologia apresenta um significativo crescimento a partir de março e decaimento brusco a partir de agosto. Caso a precipitação fosse distribuída uniformemente, teríamos uma evolução da média de chuva diária iniciando com $3 \mathrm{~mm} / \mathrm{dia} \mathrm{em}$ janeiro até quase $13 \mathrm{~mm} / \mathrm{dia}$ em junho, ocorrendo redução de quase $50 \%$ em agosto para $6 \mathrm{~mm} /$ dia e no último trimestre que é o período mais seco da região com valores abaixo dos $2 \mathrm{~mm} / \mathrm{dia}$.

\section{Tendências de chuvas no Recife}

As Figuras 4 e 5 a seguir, mostram as probabilidades de ocorrencia de chuvas divididos por intensidade de chuvas separadas por décadas, assim como separado por chuvas anuais e durante a quadra chuvosa, ou seja, a variabilidade decadal das probabilidades de ocorrência de determinados valor de chuva no ano ou na quadra chuvosa. De acordo com a Figura 4 , os dias sem chuva $(\mathrm{P}<1$ $\mathrm{mm}$ ) não ilustrados aqui, mas complementando as intensidades mostradas, estão aumentando e nas últimas três décadas passaram de $55 \%$ dos dias. As chuvas leves $(1<\mathrm{P}<10 \mathrm{~mm})$, também tiveram tendências positiva, principalmente nas últimas três décadas com incrementos de $0,3 \%$ dos dias por década e ultrapassanto um total de $28 \%$ dos dias.

Os resultados mostram que as probabilidades de ocorrência de eventos entre 10 $<\mathrm{P}<30 \mathrm{~mm}$ correspondem a $11.5 \%$ dos dias, enquanto que $3.1 \%$ dos casos foram de chuvas entre $30<\mathrm{P}<50 \mathrm{~mm}$, e apenas $1.3 \%$ de probabilidade de chuvas entre $50<\mathrm{P}<70 \mathrm{~mm}$ e em torno de $0.7 \%$ para chuvas entre $70<\mathrm{P}<100$ $\mathrm{mm}$. Para se entender melhor essa variabilidade da intensidade, podemos fazer uma análise acumulativa que aponta para a uma distribuição de chuvas acima de $10 \mathrm{~mm}$ sejam em $17 \%$ dos dias, mas dentro deste total alguns dias superaram $30 \mathrm{~mm}$ correspondendo a 5,4\% dos dias, acima de $50 \mathrm{~mm}$ em $2,4 \%$ das ocorrências e apenas em $1,1 \%$ dos dias a chuva foi maior que $70 \mathrm{~mm}$.

Uma outra análise, com relação as variabilidades temporais e tendências, indicou para chuvas fracas $(10<\mathrm{P}<30 \mathrm{~mm})$, moderadas
$(30<\mathrm{P}<50 \mathrm{~mm})$ e fortes $(50<\mathrm{P}<70 \mathrm{~mm})$ uma tendência de diminuição ao passar das décadas com padrão bem definido, enquanto que intensidades muito fortes $(70<\mathrm{P}<100 \mathrm{~mm})$ ficaram quase estacionária, sem tendência.

Um fato adicional para essa tendência na categoria muito fortes é que apresentou duas fases distintas, a primeira entre os anos de 1961 a 1990 com frequência levemente maior e inclinação mais suave, e a segunda entre 1991 e 2019, iniciando com frequencia menor, porém apresentando aumento gradual consistente, chegando no final próximo ao maior nível de probabilidade de toda a série, havendo portanto uma recuperação. Um comportamento relativamente semelhante em menor escala também ocorreram para chuvas acima de $100 \mathrm{~mm}$.

Uma das explicações possíveis se dá ao fato da década de 90 ter sofrido a ocorrência de duas grandes secas prologadas a partir dos El Nino de 1993 e 1998, que provocam subsidência no Nordeste e por isto reduzindo a potencialidade de desenvolvimento de nuvens convectivas e a frequencias de eventos mais fortes de precipitação.

$\mathrm{O}$ resultado da análise para chuvas extremas $(\mathrm{P}>100 \mathrm{~mm})$ mostra, em termos gerais, leve tendência de aumento com as passagens das décadas. Vale salientar que diferente das demais faixas de precipitação, a tendência de aumento aparece com mais suavidade e próxima de uma inclinação linear, isto indica que os eventos acima de $100 \mathrm{~mm}$ vêm aumentando de forma lenta, mas constante. $\mathrm{O}$ que mostra que eventos extremos passam a ter maior probabilidade, assim como aumentam os períodos de dias sem chuvas, ou seja, estiagens e veranicos mais comuns e chuvas extremas mais frequentes.

Os resultados sugerem ainda que esta irregularidade possa provocar uma redução nos acumulados anuais de chuva no longo prazo, pois, o aumento das chuvas leves $1<\mathrm{P}<10 \mathrm{~mm}$ e $\mathrm{o}$ pequeno aumento na frequência das chuvas extremas, não serão suficientes para cobrir as reduções ocorridas nas variações de $10<\mathrm{P}<70$ mm. De acordo com Wanderley et al., (2018) através de uma análise anual não foi possível afirmar uma tendência negativa significativa pelo teste de Mann Kendall, mas também registraram redução anual dos casos de chuvas fortes e uma fraca tendência positiva anual para chuvas extremas, principalmente a partir do ano 2002. No 
trabalho realizado por Lacerda (2015) encontrou
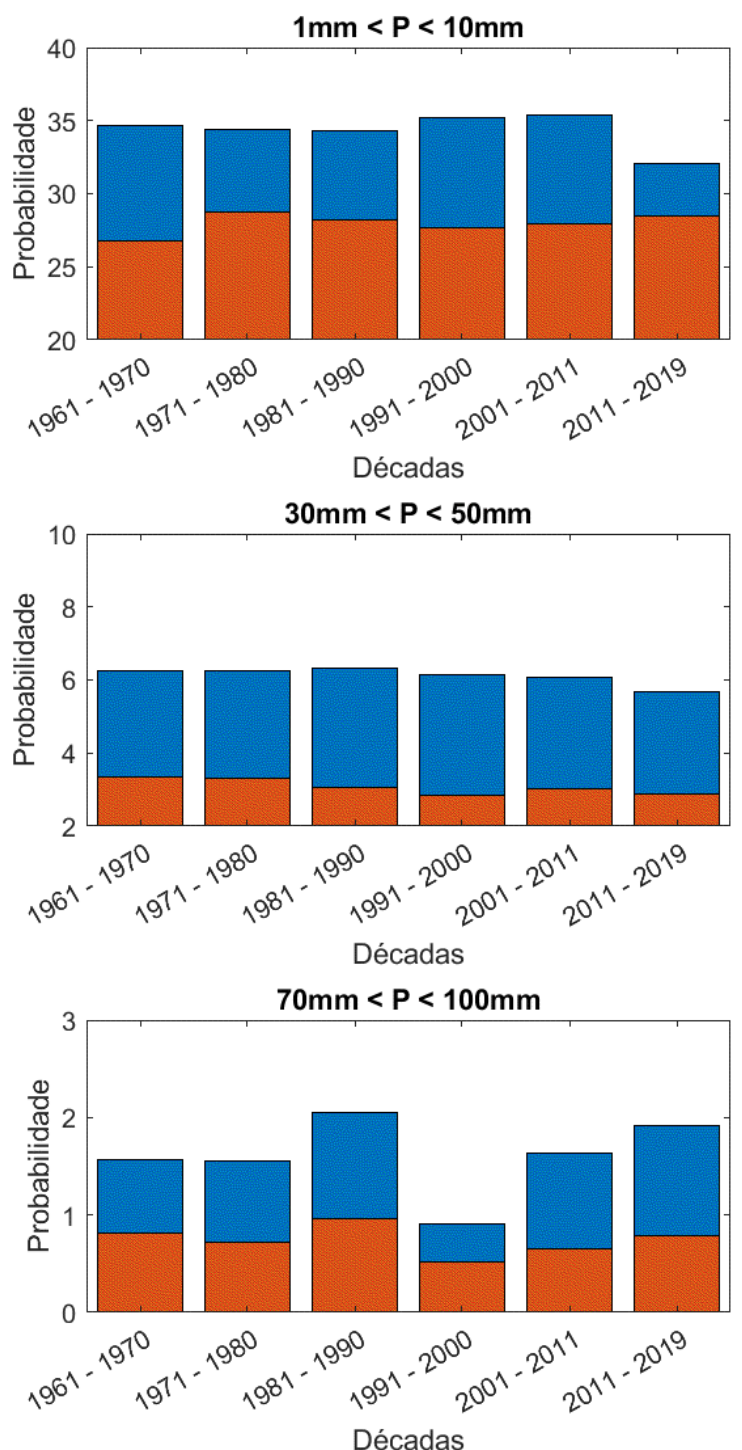

uma taxa de $-4,4 \mathrm{~mm} /$ ano para Recife
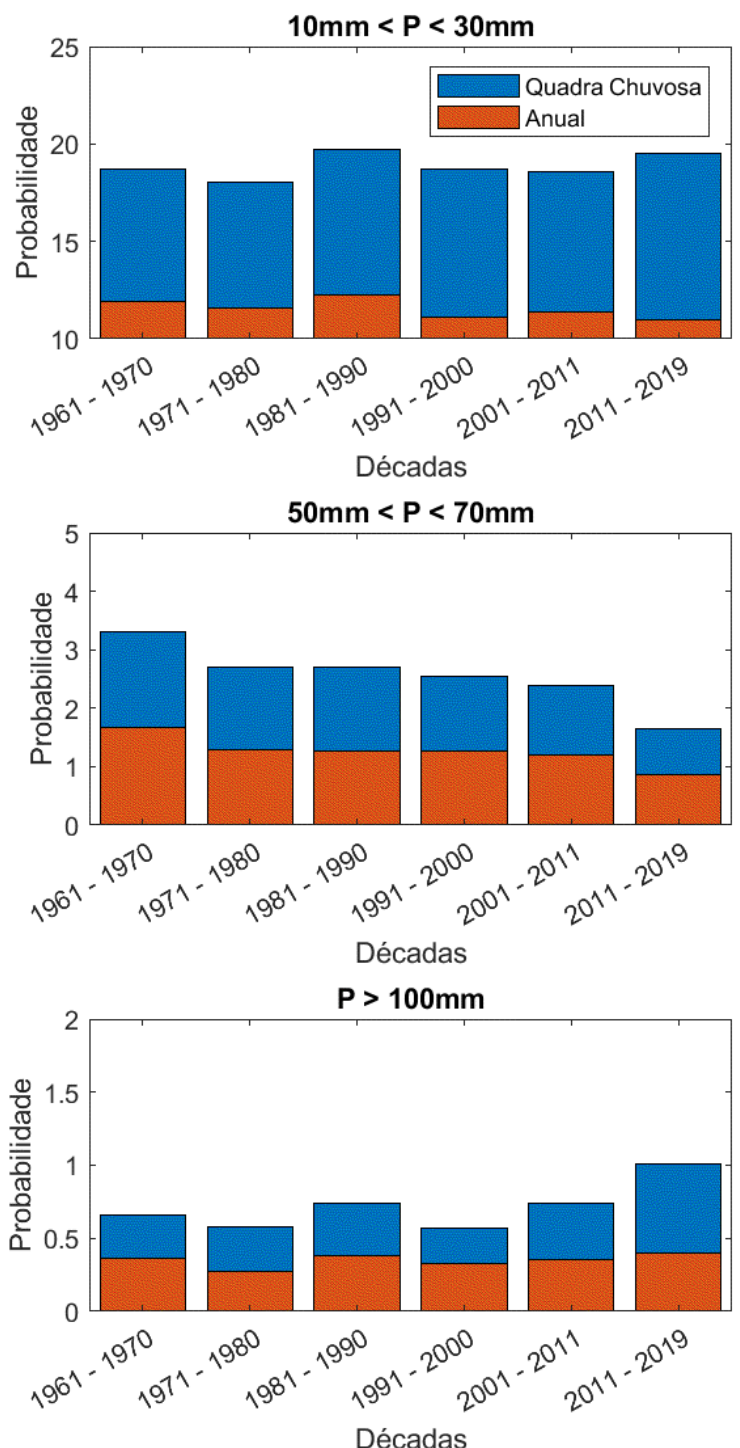

Figura 4 - Comparação das probabilidades médias da quadra chuvosa e do ano.

A Figura 5 mostra a tendência da ocorrência em cada intervalo de precipitação na escala anual, em que mostra a diferenças entre o período chuvoso (abril a julho) e anuais (janeiro a dezembro). Enquanto que os eventos de precipitação $1<\mathrm{P}<10 \mathrm{~mm}$ mantém uma tendência de aumento na escala anual, durante a quadra chuvosa este intervalo mostra uma leve tendência negativa, enquanto que há uma inversão de tendências entre as precipitações de $10<\mathrm{P}<$ $30 \mathrm{~mm}$ em que o período chuvoso mostra uma leve tendência positiva na quadra chuvosa e uma diminuição anual. No intervalo de $30<\mathrm{P}<50$ $\mathrm{mm}$ há uma tendência negativa de chuvas anuais e uma certa estabilidade na tendência do período chuvoso, comportamento que se repete no intervalo de 70 a $100 \mathrm{~mm}$. As tendências se comportam da mesma maneira apenas nos intervalos de $50<\mathrm{P}<70 \mathrm{~mm}$ (diminuindo a tendência) e acima de $100 \mathrm{~mm}$ com aumento de tendência nos dois período, anual e quadra. 
Este resultado indica que existe uma mudança no comportamento de chuvas no Recife. Devido ao período seco possuir menores valores de chuva, os dados indicam que existe uma forte tendência de diminuição de chuvas entre janeiro e março esteja influenciando nas chuvas com
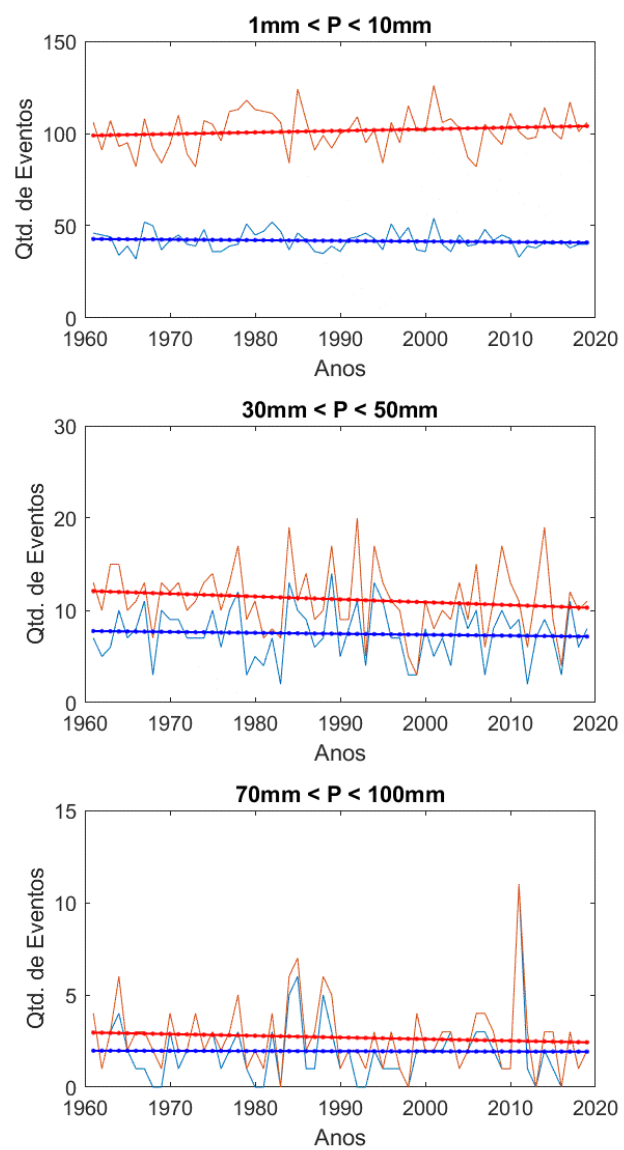

Figura 5 - Tendência da quantidade de eventos por faixa de intensidade das chuvas

\section{Tendências de temperatura e umidade no Recife}

A análise dos dados de temperatura máxima (Tmax), temperatura mínima (Tmin), umidade relativa (Ur), associada ao comportamento das precipitações, facilita a compreensão da variabilidade do clima em Recife, e as tendências conjuntas destas variáveis intervalo de 30 a $100 \mathrm{~mm}$. Este período está associado com os eventos meteorológicos provindo da Zona de Convergência Intertropical ZCIT e também aos Vórtices Ciclônico de Altos Níveis - VCAN.
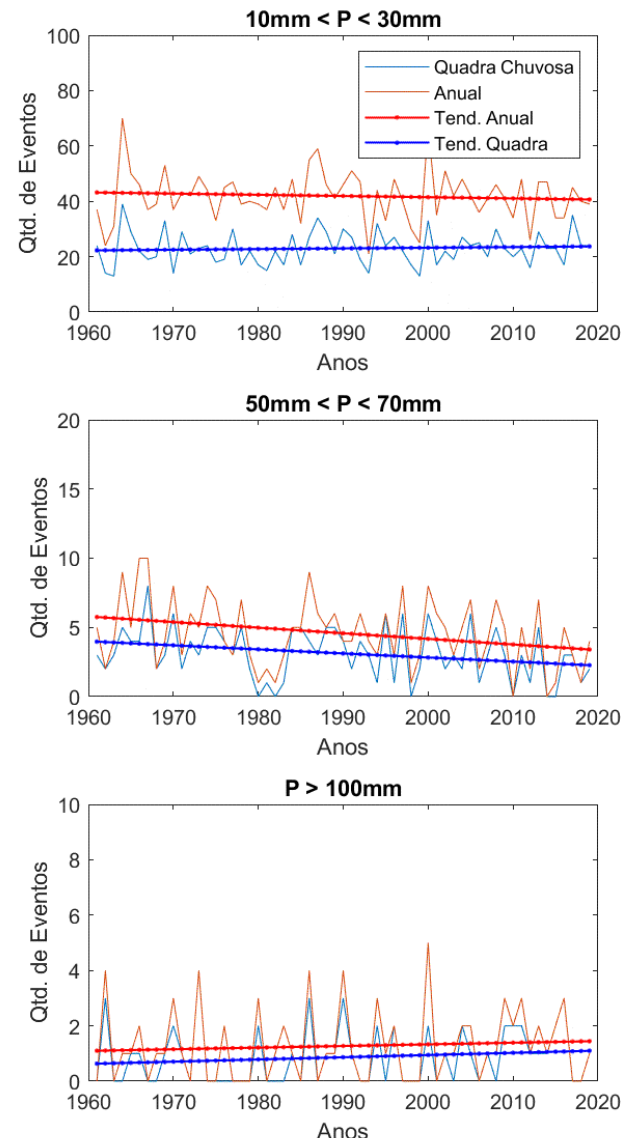

Tabela 4 - Taxa de variação de Temperatura e umidade por década de 1961 a 2019.

\begin{tabular}{cc}
\hline Var & Taxa de Variação por Década \\
\hline TMin & 0,135 \\
TMax & 0,227 \\
Ur & $-0,534$ \\
\hline
\end{tabular}

O comportamento das temperaturas mensais pode ser observada na Figura 6, na qual indica aumento da TMáx para todos os meses do permitem identificar anomalias e mudanças nos padrões locais. Os primeiros cálculos (Tabela 4) identificaram aumento da Tmáx com uma taxa média de $0.23^{\circ} \mathrm{C} /$ Década, Tmín com acréscimo de $0.13^{\circ} \mathrm{C} /$ Década e redução da Ur com $-0.53 \%$ / Década. ano. Já para a Tmín, embora tenha apresentado aumento na maioria dos meses, foi encontrado uma certa estabilidade entre abril e julho, que 
corresponde a quadra chuvosa do Recife, indicando um comportamento anômalo ao padrão de aquecimento do restante do ano. É importante destacar que a última década a série da TMin apresentando uma taxa de $-0.8^{\circ} \mathrm{C} /$ década. $\mathrm{Na}$ Figura 6 é possível observar que o final da série se posiciona abaixo da linha da tendência.

A umidade relativa média do ar, de forma inversa da temperatura, indica redução em todos os meses, de forma mais suave entre junho e outubro. Conforme a Figura 7, os valores giram em torno de $80 \%$, ficando acima entre abril e agosto, e abaixo entre setembro e fevereiro, destacando março como mês de transição desse limiar. Observou-se que a maior desaceleração da umidade ocorreu na década de 1990 com redução média de $-3 \%$ no mês de março por exemplo, porém, a continuidade da série de Ur mostra que a década atual estão constantemente sendo mais secas que as décadas de anteriores.
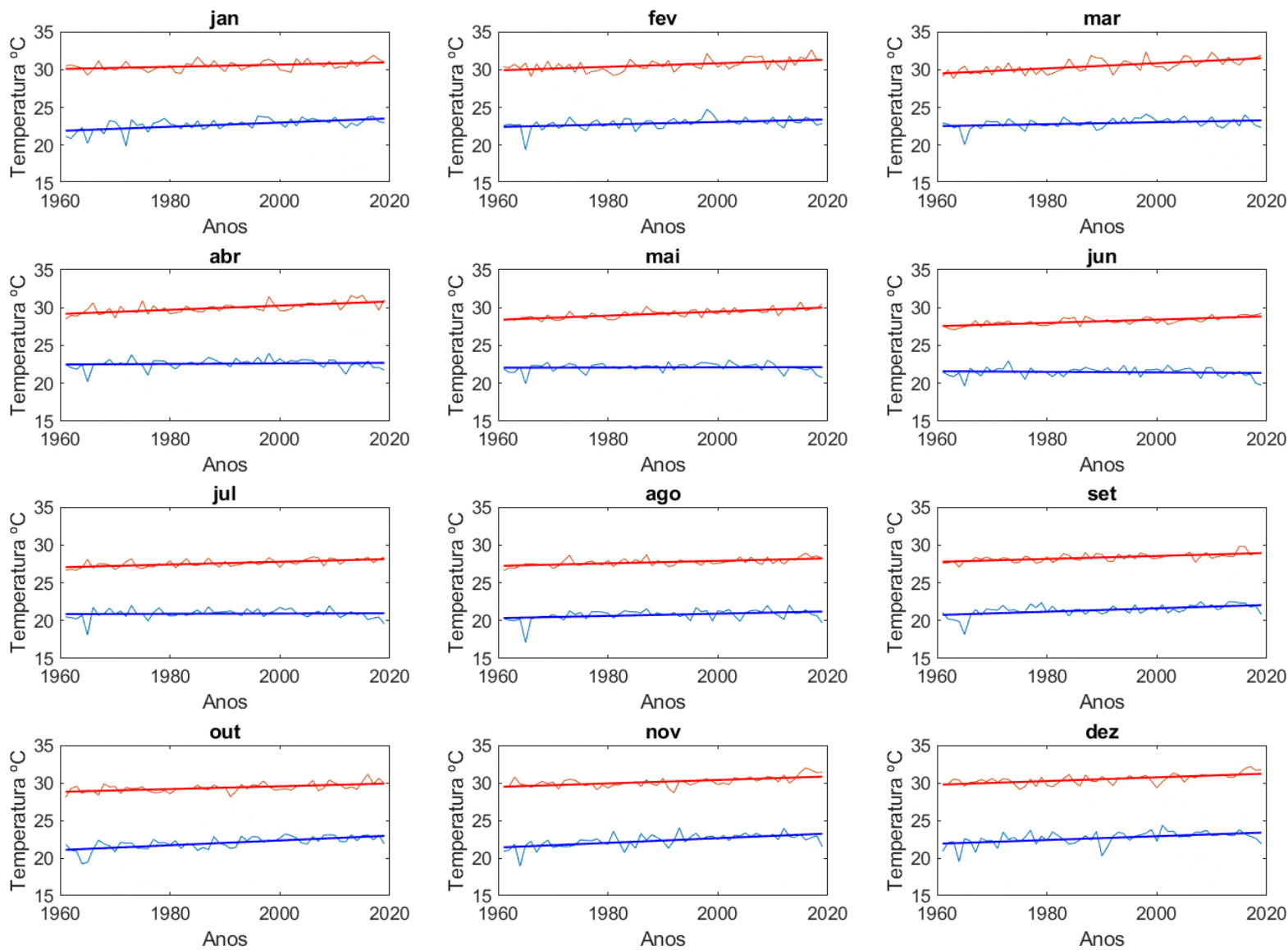

Figura 6 - Tendência mensal de temperatura máxima e mínima média.

Guedes, R. S. G. \& Silva, T. L. V. 

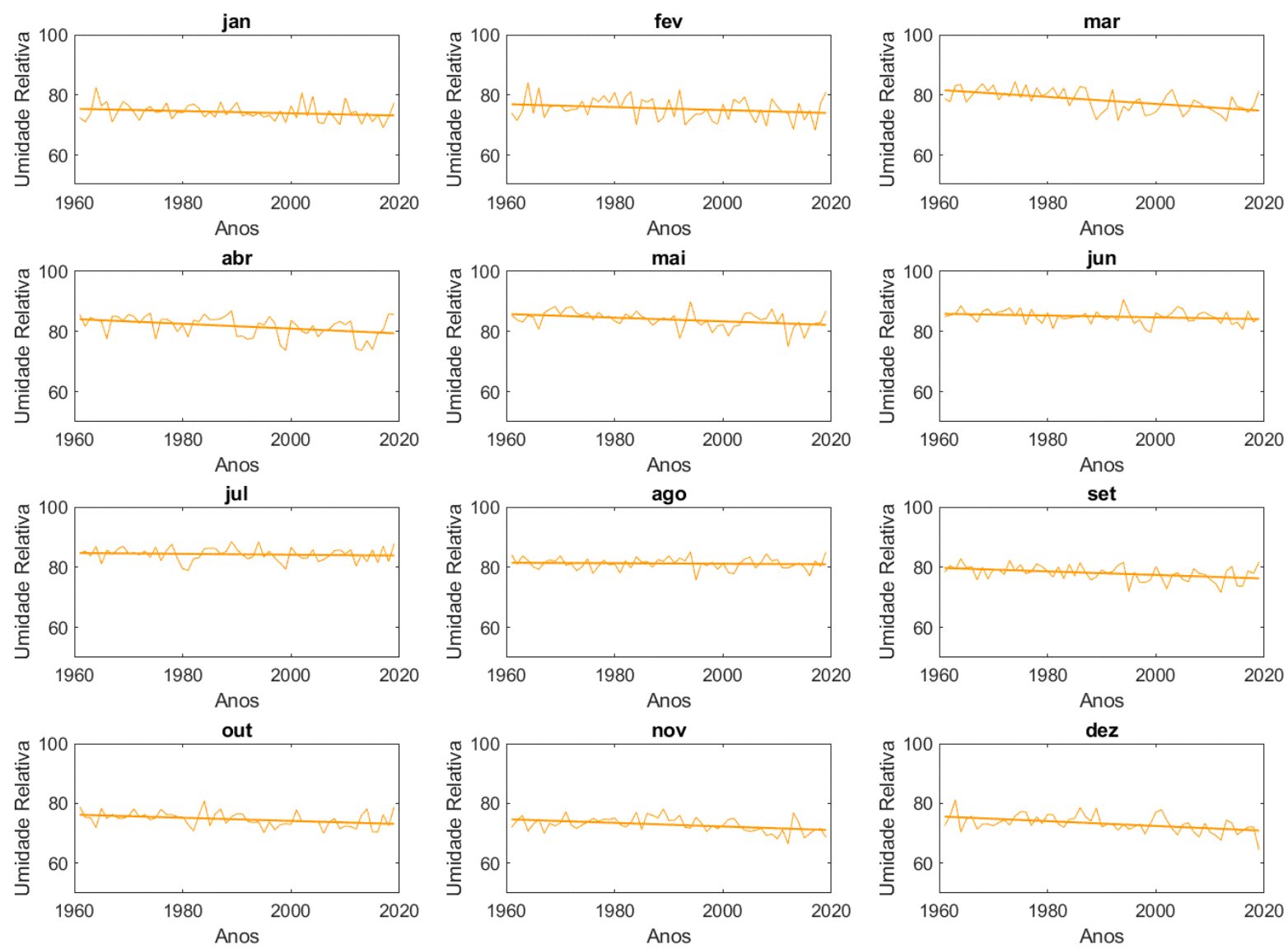

Figura 7 - Tendência mensal de umidade relativa média.

A tabela 5 mostra os valores da tedência média ocorrida em cada mês durante os 59 anos analisados, e destacou-se que a umidade relativa teve redução em todos os meses, com maior declínio em março, seguido de abril e maio, o comportamento inverso ocorreu na Temperatura máxima com aumento todos os meses e pico em março, seguido de abril e maio, esse comportamento pode indicar uma mudança no padrão climático na transição do verão para o outono, e também com atraso do inicio do período chuvoso, indicando as reduções das chuvas de março na região do Litoral. Observa-se também que a temperatura mímina apesar do aumento em 8 meses, os 4 meses da quadra chuvosa ficaram estáveis.

Tabela 5. Taxa decadal para cada mês das temperaturas e umidades.

\begin{tabular}{ccccccccccccc}
\hline Var & Jan & Fev & Mar & Abr & Mai & Jun & Jul & Ago & Set & Out & Nov & Dez \\
\hline TMin & 0,23 & 0,14 & 0,10 & $\mathbf{- 0 , 0 1}$ & $\mathbf{- 0 , 0 4}$ & $\mathbf{- 0 , 0 7}$ & $\mathbf{- 0 , 0 1}$ & 0,16 & $\mathbf{0 , 2 8}$ & $\mathbf{0 , 3 1}$ & $\mathbf{0 , 2 9}$ & 0,24 \\
TMax & 0,16 & 0,17 & $\mathbf{0 , 3 3}$ & $\mathbf{0 , 3 0}$ & $\mathbf{0 , 2 7}$ & 0,25 & 0,18 & 0,21 & 0,21 & 0,17 & 0,24 & 0,24 \\
Ur & $-0,56$ & $-0,47$ & $\mathbf{- 1 , 0 6}$ & $\mathbf{- 0 , 8 6}$ & $\mathbf{- 0 , 6 3}$ & $-0,41$ & $-0,18$ & $-0,27$ & $-0,49$ & $-0,33$ & $-0,43$ & $-0,72$ \\
\hline
\end{tabular}

A partir da Figura 8 observa-se as variabilidades sazonais de temperatura e umidade relativa, e encontrou-se maior aquecimento na estação do outono com $0.29^{\circ} \mathrm{C} /$ década de temperatura máxima e devido a estabilidade da Tmin nesse período, está ocorrendo um aumento da amplitude térmica, enquanto que para a primavera o destaque foi para Tmin com $0.30^{\circ} \mathrm{C} /$ década com aumento um pouco mais acelado que a Tmáx e por isto apresenta leve redução da amplitude. Na estação do verão as duas linhas são parelelas e positivas com aquecimento similar durante o dia e a noite. No inverno há maior incremento durante o dia, e o período na noite o incremento ocorre apenas na segunda metade da estação. 

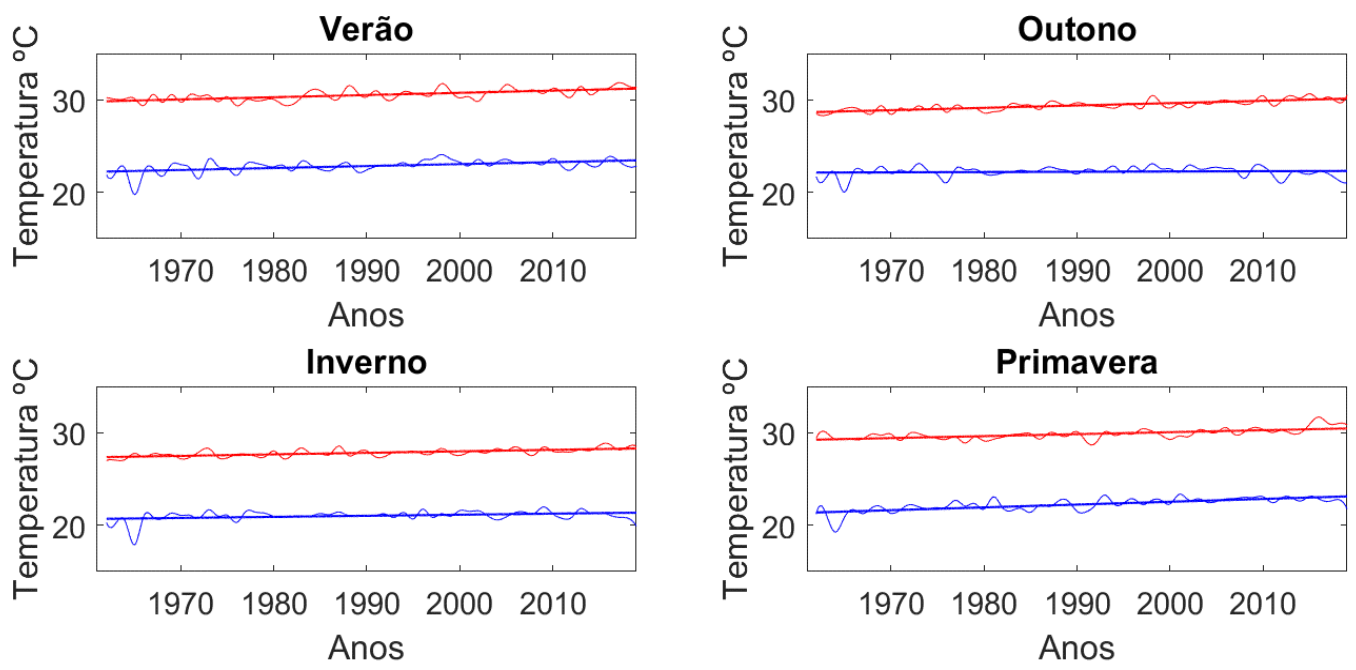

Figura 8 - Tendência sazonal da temperatura máxima e mínima média.

O comportamento sazonal da Ur mostrado na Figura 9, indica que no inverno a umidade possui tendência levemente decrescente. Isto pode estar relacionado com o fluxo de umidade do oceano para o continente, que se dá com maior intensidade neste período do ano (Cavalcanti et al., 2002). Vale observar que no início da série a umidade relativa nos meses do outono eram maiores do que as registradas no inverno, tendo médias em torno de $85 \%$, enquanto que no inverno em torno de $82 \%$, no final da série ambos com valores médios em torno de $80 \%$. Conforme a Tabela 6, o inverno apresenta apenas $0,26 \%$ /década, uma oscilação mais lenta comparada as estações do verão e outono.
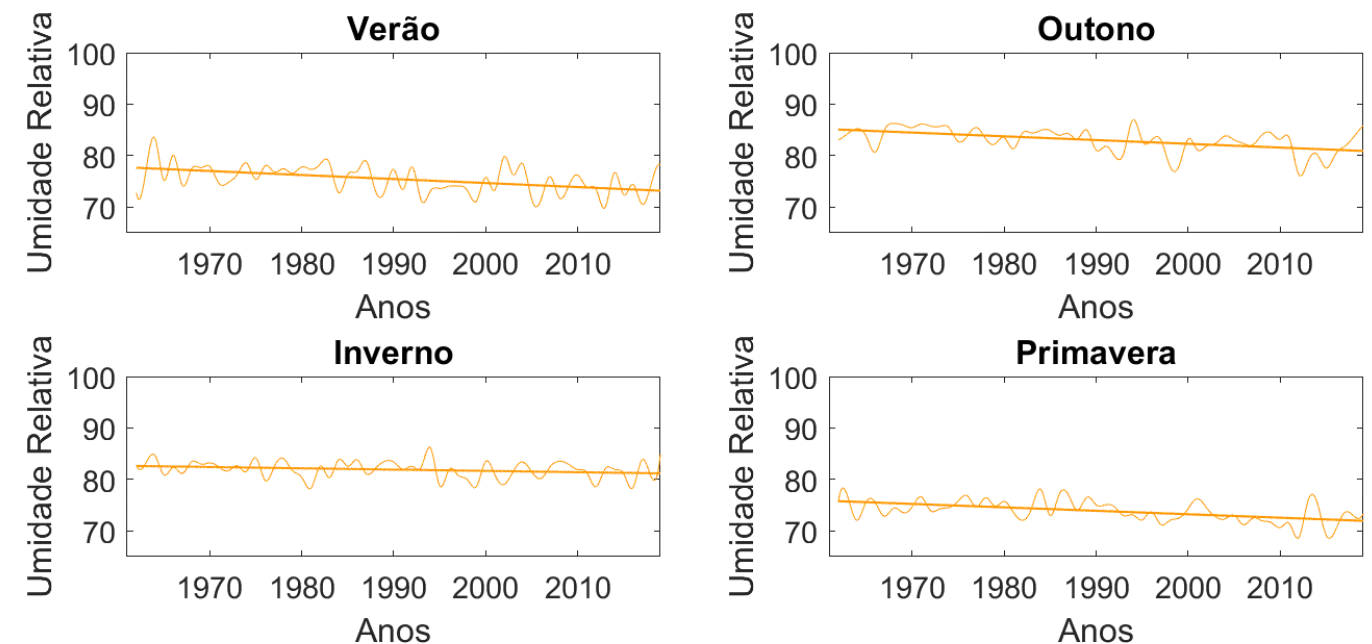

Figura 9 - Tendência sazonal da temperatura máxima e mínima média.

A Tabela 6 mostra um resumo das taxas de variação decadal para cada estação do ano em Recife. A umidade relativa indica que o outono aparece com redução mais acentuada do que as demais estações do ano. O resultado mostra que os dias no Recife estão ficando $0.227^{\circ} \mathrm{C}$ maior a cada década, mostrando um aumento constante, sendo o outono com maior aquecimento que as demais estações. Já para temperatura mínima, a primavera mostra noites mais quentes, enquanto que no outono a temperatura mínima aparece mais estável. Lacerda (2015) indicou que no período seco a taxa Tmin foi maior, enquanto que no período chuvoso a Tmáx foi mais acelerada, corroborando com este trabalho, porém, em termos gerais encontramos maior aceleração da 
temperatura máxima diferente da citação que encontrou predominância do aumento da Tmin, este fato pode ser explicado pela última década que reduziu as taxas da Tmin.

Tabela 6. Variação médias decadal para cada estação do ano.

\begin{tabular}{ccccc}
\hline Variável & Verão & Outono & Inverno & Primavera \\
\hline TMin & 0,19 & $-0,03$ & 0,12 & 0,30 \\
TMax & 0,22 & 0,29 & 0,19 & 0,22 \\
Ur & $-0,69$ & $-0,76$ & $-0,26$ & $-0,44$ \\
\hline
\end{tabular}

As densidades de probabillidades de extremos de temperatura foram expostas na Figura 10, na qual selecionou-se 3 períodos climatológicos, com deslocamento temporal de 15 anos entre cada período de 30 anos de climatologia, possibilitando observar a transição entre os mesmos.

O deslocamento dos gráficos para a direita, além de indicar o aumento do valor central de maior probabilidade, passando de $29,1^{\circ} \mathrm{C}$ para $29,8^{\circ} \mathrm{C}$ entre $1961-1991$ e $1991-2019$ para a Tmáx, e o pico da Tmin passando de $20,5^{\circ} \mathrm{C}$ para $21,2^{\circ} \mathrm{C}$, mostra principalmente uma redução nas probabilidades de ocorrência dos valores menores de temperatura e um aumento das probabilidades para os valores maiores. Ainda, observa-se o achatamento dos picos de probabilidades assim como o enlargamento das bases das curvas, o que mostra que os valores de maior intensidade de temperatura estão maiores do que os valores médios, indicando que as anomalias estão ficando mais acentuadas e mais prováveis monstrando que os eventos de ondas de calor estão ficando mais prováveis de ocorrer e mais constantes.

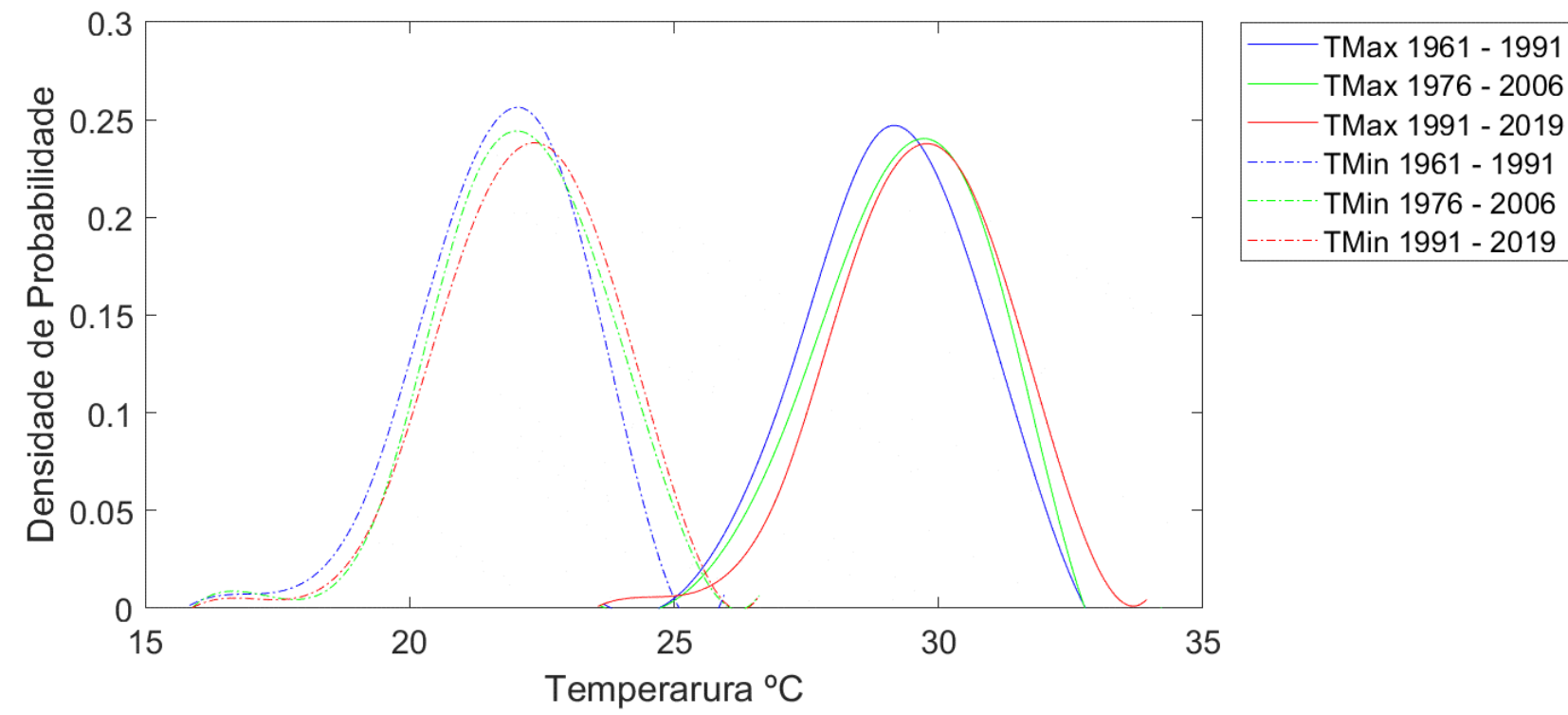

Figura 10 - Função densidade de probabilidade de temperatura máxima (contínuo) e mínima (pontilhada) das décadas: Azul - 1961 a 1991; Verde - 1976 a 2006; Vermelho - 1991 a 2019.

\section{Discussões}

As mudanças nas geografias das cidades brasileiras estão mudando consideravelmente as propriedades climáticas destas áreas, isto deve impactar mais problemas socioeconômicos. Em um cenário de mudança climática, é muito provável que a faixa leste do Nordeste Brasileiro tenha um aumento na vulnerabilidade climática, principalmente relacionado com chuvas torrenciais, deslizamento de massa e alagamentos (Debortoli et al., 2017).

Este trabalho com dados atualizados até o ano de 2019, acrescenta informações nas escalas decadais e intra-anuais, e forneceu mais detalhes sobre as mudanças da sazonalidade, distinção do período chuvoso e transições entre estações através de escalas mensais, e com isto apontou 
para os períodos de maiores probabilidades de ocorrência de extremos de chuva e ondas de calor.

Os resultados encontrados indicam que as tendências das variáveis meteorológicas não seguem de forma linear com o avanço das décadas sugerindo variabilidades decadais influenciando a climatologia. As variações de tendência encontradas apontam a existência de variabilidades cíclicas em um ambiente com mudança climática. Este resultado mostra que as variabilidades climáticas globais como El Niño, Dipolo do Atlântico e demais Oscilações oceânicas (Andreoli e Kayano, 2006, 2007; Aragão, 1998; Moura e Shukla, 1981; Silva et al., 2018; Silva e Guedes, 2012), as quais influenciam diretamente nas variabilidades climáticas locais por meio das teleconexões (Michel et al., 2020), atuam de forma a acelerar ou desacelerar as taxas das tendências decadais da mudança do clima regional.

As variações mensais e sazonais apresentam comportamento distintos dentro da tendência anual. Cada período apresentaram tendências diferentes, como por exemplo, o verão apresentando maior aquecimento e mais seco nas últimas décadas; o inverno com baixa queda de umidade; e as estações de transições com maior taxa de alteração em seus padrões climáticos, em que a primavera registrou noites mais aquecidas, e o outono a maior queda de umidade e taxa de aceleração do dia, fato que pode indicar a alteração do início do período chuvoso do Recife. Estudo realizado por Golroubary et al., (2018) mostra que as Ilhas de Calor afetam as precipitações diferentemente em cada período do ano, bem como as ilhas de calor são mais significativa em centros urbanos mais adensados.

As alterações na temperatura e umidade do Recife, além da influência de forçantes externas, podem ter contribuição também das ilhas de calor urbana devido à expansão da Região Metropolitana do Recife para dentro do continente. $\mathrm{O}$ efeito da urbanização desenfreada altera $o$ balanço de energia aumentando a temperatura da cidade em relação aos locais rurais em sua volta (Mirzaei et al., 2020) aumentando o nível de desconforto humano Gomes (2019). Vale salientar que a estação meteorológica dos dados estudados estão em uma área afastada do centro da Cidade e por isto esta contribuição deve ser menos acentuada.

Conforme os resultados indicaram que mais de $90 \%$ das chuvas são abaixo dos $30 \mathrm{~mm}$, apontando que a maioria dos dias ocorre atuação de sistemas pequenos, com maior frequência de chuvas à noite e início da manhã conforme Anjos (1998), apoiados pelo efeito brisa. Porém, o encontrado aumento da temperatura e redução da umidade deve dificultar chuvas de menor escala e isto pode ser um dos fatores para as chuvas menos intensas estarem apresentando tendência negativa, e por isto o total anual também está sendo prejudicado.

Ainda, estas mudanças tem menos impacto durante o período chuvoso, especialmente na quadra chuvosa conforme os resultados mostraram, não apenas pelos níveis de umidade serem maiores nesse período, mas também pela atuação de sistemas oceânicos de meso e grande escalas que transportam bastante umidade, como VCAN, ZCIT, DOL, entre outras perturbações, que carregam bastante energia para vencer barreiras locais e ainda provocar chuvas significativas, apesar de algumas perdas. Supõe-se ainda que devido esses sistemas serem convectivos, quando possuem grande potencial energético é provável que ao encontrarem uma região mais aquecida se desenvolva provocando chuvas intensas, o que justificaria o aumento das chuvas acima de $100 \mathrm{~mm}$ para condições específicas.

O estudo mostrado por Lenderink e Van Meijgaard (2010) que num ambiente mais aquecido (Temperatura de orvalho $-\mathrm{Td}+1^{\circ} \mathrm{C}$ ), a retenção de vapor de água se dá com maior intensidade (> 7\%), sendo as chuvas intensas sensíveis a umidade relativa do ar alta. Com isso, sugere que o aumento da temperatura máxima (diurna) faz com que as chuvas durante o dia tenham menor probabilidade de ocorrência do que durante a noite/madrugada/primeiras horas da manhã no Recife em que recebe influência de uma umidade relativa mais alta, sendo mostrado por Anjos e Anjos (1986). A temperatura parece ser mais influente nas precipitações de curto tempo (pancadas) do que nas precipitações de longo período, mostrando um maior pico de precipitações em escalas sub-diárias (Schroeer e Kirchengast, 2018), porém, existe a necessidade de mais estudos para confirmar estas características.

Alguns estudos, como o de Gomes (2019) mostrou que nas áreas de periferia do Recife existe uma predominância de desconforto térmico no período de outubro, devido as barreiras aglomeradas para o escoamento do vento, pouca 
arborização e urbanização desorganizada que favorecem o acúmulo de calor sob a superfície. Confrontando com os dados encontrados neste trabalho, pode-se inferir um futuro agravamento na sensação térmica sobre a cidade $\mathrm{e}$ principalmente nas periferias, visto a maiores probabilidades de ondas de calor acima de $34^{\circ} \mathrm{C}$ no Recife.

Para averiguar os impactos de mesoescala e outras forçantes externas, bem como a influências de indicadores globais, é necessário a expansão deste trabalho. É importante frisar que apesar deste estudo ter uma análise pontual das climatologias de chuva, temperaturas e umidade, os dados mostram que na média climática, há indicativos do aumento de ondas de calor e que o Recife está passando por mudanças climáticas que afetará a vida da sociedade recifense, mostrando a necessidade de ações de mitigação e adaptação da cidade às novas perspectivas.

\section{Conclusões}

É necessário uma política rígida de controle dos dados que preserve a localização, e assiduidade das manutenções corretivas e coletas dos dados meteorológicos, frente a dificuldade operacional e frequência de substituições, aditivos e mudanças de postos. Conclui-se que existe a necessidade de garantias de recursos para manter fixa uma rede mínima de equipamentos com qualidade para construção de longas séries históricas e expansão dos estudos climáticos.

Os valores de chuva acima de $50 \mathrm{~mm}$ podem ocorrer em todos os meses do período chuvoso, com uma frequencia de 8 vezes por ano. Acima de $70 \mathrm{~mm}$ possui grande chance de ocorrer pelo menos 3 vezes por ano, enquanto que valores acima de $100 \mathrm{~mm}$ é mais incerto com a frequencia próximo de 1 evento anual. O que significa que no Recife existe ao menos 3 eventos muito forte por ano e 1 evento extremo a cada 2 anos. Esses eventos significativos são frequentes no outono e inverno e quase nulos na primavera e verão.

A análise decadal das chuvas indicou uma diminuição das chuvas no acumulado anual, a redução é mais definida nas faixas de chuvas fracas $(10<\mathrm{P}<30 \mathrm{~mm})$, moderadas $(30<\mathrm{P}<50$ $\mathrm{mm})$ e fortes $(50<\mathrm{P}<70 \mathrm{~mm})$, enquanto que a categoria muito forte $(70<\mathrm{P}<100 \mathrm{~mm})$ foi quase estável aumentando nas últimas três décadas. $\mathrm{O}$ comportamento inverso foi observado para os dias sem chuva que aumentaram assim como chuvas leves $(1<\mathrm{P}<10 \mathrm{~mm})$, e chuvas intensas $(\mathrm{P}>100$ $\mathrm{mm})$ também apresentaram tendência de aumento de forma mais suave, isto pode indicar estiagens e veranicos mais comuns e chuvas extremas mais frequentes. Importante destacar que a quadra chuvosa apresentou menos variação, e basicamente quatro faixas de intensidade se mantiveram estáveis, apenas a categoria forte teve redução e a categoria chuva intensa aumentou.

A década de 90, devido os dois grandes El Niños, impactaram a tendência de aumento das chuvas acima de $70 \mathrm{~mm}$ naquele período, porém, esse aumento foi retomado posteriormente, indicando que a interferência dos sistemas atuantes na região tem efeito temporário, mas não modifica a tendência que está em curso.

As temperaturas máximas estão aumentando em todos os meses, de forma mais acelerada no outono, e acumulou uma taxa de $0,23^{\circ} \mathrm{C} /$ década. Enquanto a temperatura mínima também indica noites mais quentes na média do ano, porém, o outono apresenta estabilidade e a primavera tem a maior aquecimento noturno, com isto a Tmin acumulou uma taxa de 0.13 graus por década, assim a amplitude térmica aumentou no outono e reduziu na primavera. Ainda, a comparação climatológica indica um deslocamento de aquecimento do padrão médio das temperaturas, tanto do dia quanto da noite, e isto aumentou as probabilidades para ocorrência de valores cada vez maiores.

A umidade relativa apresentou tendência negativa em todos os meses, com uma taxa acumulada de $-0.5 \% /$ década, sendo mais acentuada entre o verão e o outono, com destaque para o mês de março, com uma taxa média de $1.06 \% /$ década.

As temperaturas máximas estão afetando o comportamento médio ao longo prazo, com tendência mais forte no período entre 2010 e 2019. Observa-se que essa mudança são menos acentuadas para as temperaturas mínimas no outono, alterando a amplitude térmica. Estas tendências em curso indicam que as probabilidades de ocorrência de ondas de calor no Recife estão maiores e com maior intensidade do que décadas passadas.

Conclui-se que o Recife passa por um processo de mudança climática, com diferentes níveis de variação entre escalas sazonais, anuais e decadais, com maior impacto fora da quadra chuvosa. Os indicativos são de aumento dos dias sem chuva e aumento relativo dos eventos de 
chuvas extremas, com sequencial aumento das temperaturas do dia, menor taxa no período noturno e persistente redução na umidade do ar.

Este comportamento pode ser extensivo a outras áreas do Nordete, em especial a faixa leste, de acordo com o conjunto de referências e resultados deste trabalho, porém, um estudo abrangendo toda região Nordeste é imprescindível para destacar as varições da escala temporal e de intensidade apotandas neste trabalho.

\section{Agradecimentos}

Os autores agradecem ao Instituto Nacional de Meteorologia (INMET) pela disponibilidade dos dados e Agência Pernambucana de Águas e Clima (APAC) pelo apoio à pesquisa.

\section{Referências}

Andreoli, R.V., Kayano, M.T., 2006. Tropical pacific and south atlantic effects on rainfall variability over northeast brazil. International Journal of Climatology, 26, 1895-1912.

Andreoli, R.V., Kayano, M.T., 2007. A importância relativa do atlântico tropical sul e pacífico leste na variabilidade de precipitação do Nordeste do Brasil. Revista Brasileira de Meteorologia. 22, 63-74.

Anjos, B.L., Anjos, R.J., 1986. Característica da Precipitação no Recife. I Congresso Interamericano de Meteorologia e IV Congresso Brasileiro de Meteorologia. Brasília, 242-247.

Anjos, R.J., 1998. Variabilidade das chuvas máximas em 24 Horas no Recife - PE. p. 1200-1203.

APAC - Agência Pernambucana de Águas e Clima. Disponível em: http://www.apac.pe.gov.br/meteorologia/monit oramento-pluvio.php. Acessado em 07/06/2020.

Aragão, J.O.R., 1998. O Impacto do ENSO e do Dipolo do Atlântico no nordeste do Brasil. Bulletin de I'Institut français d'études andines, 27, 839-844.

Cavalcanti, E.P., Gandu, A.W., Azevedo, P.V., 2002. Transporte e balanço de vapor d'água atmosférico sobre o nordeste do brasil. Revista Brasileira de Meteorologia, 17, 207-217.

Costa, M.B.S.F., Mallmann, D.L.B., Pontes, P.M., Araujo, M., 2010. Vulnerability and impacts related to the rising sea level in the Metropolitan Center of Recife, Northeast Brazil. Pan-American Journal of Aquatic Sciences, 5, 169-177.

Debortoli, N.S.; Camarinha, P.I.M.; Marengo, J.A.; rodrigues, R.R., 2017. An index of Brazil's vulnerability to expected increases in natural flash flooding and landslide disasters in the context of climate change. Natural Hazards. $86,557-582$.

Ebi, K.L., Nealon, J., 2016. Dengue in a changing climate. Environmental Research, 151, 115123.

Fereira, A.G., Melo, N.G.D.S., 2005. Principais sistemas atmosféricos atuantes sobre a região Nordeste do Brasil e a influência dos Oceanos. Revista Brasileira de Climatologia, 1, 15-28.

Golroudbary, V.R.; Zeng, Y.; Mannaerts, C.M.; Su, Z., 2018. Urban impacts on air temperature and precipitation over the netherlands. Climate Research. 75, 95-109.

Gomes, H.B., Ambrizzi, T., Herdies, D.L., Hodges, K., Silva, B.F.P., 2015. Easterly Wave Disturbances over Northeast Brazil: An Observational Analysis. Advances in Meteorology. 2015, 1-20.

Gomes, J. H., Silva, Silva, T.L.V., Guerra, E.R., Anastácio, D.T.D., 2012. Ocupação em Área de Risco de Deslizamentos no Córrego do Jenipapo, Recife, Pernambuco. Revista Brasileira de Geografia Física. 03, 524-539.

Hänsel, S., Medeiros, D.M., Matschullat, J., Petta, R.A., Silva, I.M., 2016. Assessing Homogeneity and Climate Variability of Temperature and Precipitation Series in the Capitals of North-Eastern Brazil. Frontiers in Earth Science. 4, 1-21.

Hastenrath, S. 2012. Exploring the climate problems of Brazil's Nordeste: A review. Climatic Change, 112, 243-251.

IBGE - Instituto Brasileiro de Geografia e Estatística. Disponível em: https://cidades.ibge.gov.br/brasil/pe/recife/pan orama. Acessado em 07/06/2020.

INMET - Instituto Nacional de Meteorologia. Disponível em: http://www.inmet.gov.br/portal/index.php?r=b dmep/bdmep. Acessado em 07/06/2020.

Kouadio, Y.K., Servain, J., Machado, L.A.T., Lentini, C.A.D., 2012. Heavy Rainfall Episodes in the Eastern Northeast Brazil Linked to Large-Scale Ocean-Atmosphere Conditions in the Tropical Atlantic. Advances 
in Meteorology. 2012, 1-16.

Lacerda, F.F., 2015. Tendências de temperatura e precipitação e cenários de mudanças climáticas de longo prazo no Nordeste do Brasil e em ilhas oceânicas. Tese (Doutorado). Recife, Universidade Federal de Pernambuco - UFPE.

Lenderink, G., Meijgaard, E. V., 2010. Linking increases in hourly precipitation extremes to atmospheric temperature and moisture changes. Environmental Research Letters, 5.

Marengo, J. A., 2007. Mudanças Climáticas Globais e Efeitos sobre a Biodiversidade. Sub projeto: Caracterização do clima atual e definição das alterações climáticas para o território brasileiro ao longo do Século XXI (Relatório $\mathrm{n}^{\circ}$ 1: Caracterização do clima no Século XX e Cenários Climáticos no Brasil e na América do Sul para o Século XXI derivados dos Modelos Globais de Clima do IPCC). Ministério do Meio Ambiente. CPTEC/INPE. São Paulo.

Marengo, J.A., Alves, L.M., Alvala, R.C.S., Cunha, A.P., Brito, S., Moraes, O.L.L., 2017. Climatic characteristics of the 2010-2016 drought in the semiarid Northeast Brazil region. Anais da Academia Brasileira de Ciências. 1-13.

Michel, C.; Li, C.; Simpson, I.R.; Bethke, I.; King, M. P.; Sobolowski, S., 2020. The change in the ENSO teleconnection under a low global warming scenario and the uncertainty due to internal variability. Journal of Climate. 33, 4871-4889.

Mirzaei, M.; Verrelst, J.; Arbabi, M.; Shaklabadi, Z.; Lotfizadeh, M., 2020. Urban heat island monitoring and impacts on citizen's general health status in Isfahan metropolis: A remote sensing and field survey approach. Remote Sensing, 12, 1-17.

Moscati, M.C.L.; Gan, M.A., 2007. Rainfall variability in the rainy season of semiarid zone of northeast Brazil (NEB) and its relation to wind regime. International Journal of Climatology, 27, 493-512.

Moura, A.D., Shukla, J., 1981. On the dynamics of droughts in Northeast Brazil: Observations, theory, and numerical experiments with a general circulation model. Journal of Atmospheric Sciences, 38, 2653-2675.

Paegle, J.N., Mo, K.C., 2002. Linkages between summer rainfall variability over south america and sea surface temperature anomalies. Journal of Climate, 15, 1389-1407.
Prefeitura municipal do Recife., 2019. Análise de riscos e vulnerabilidades climáticas e estratégia de adaptação do município do Recife. p. 52.

Prefeitura municipal do Recife - Disponível em: http://www2.recife.pe.gov.br/pagina/caracteriz acao-do-territorio. Acessado em 07/06/2020.

Ramos, R.P.L., 1975. Precipitation characteristics in the Northeast Brazil dry region. Journal of Geophysical Research. 80, 1665-1678.

Rao, V.B., Lima, M.C., Franchito, S.H., 1993. Seasonal and Interannual Variations of Rainfall over Eastern Northeast Brazil. Journal of Climate. 6, 1754-1763.

Rodrigues, R.R., Haarsma, R.J., Campos, E.J.D., Ambrizzi, T., 2011. The impacts of inter-El Niño variability on the tropical Atlantic and northeast Brazil climate. Journal of Climate. 24, 3402-3422.

Schroeer, K., Kirchengast, G., 2018. Sensitivity of extreme precipitation to temperature: the variability of scaling factors from a regional to local perspective. Climate Dynamics. 50, 3981-3994.

Silva, D.F., Lima, M.J.S., Neto, P.F.S., Gomes, H.B., Silva, F.D.S., Almeida, H.R.R.C., Pereira, M.P.S., Costa, R.L., 2020. Caracterização de eventos extremos e de suas causas climáticas com base no Índice Padronizado de Precipitação Para o Leste do Nordeste. Revista Brasileira de Geografia Física 13, 449-464.

Silva, T.L.V., Veleda, D., Araújo, M., Tyaquiçãa, P., 2018. Ocean-atmosphere feedback during extreme rainfall events in eastern Northeast Brazil. Journal of Applied Meteorology and Climatology. 57, 1211-1229.

Silva, T.V.L, Guedes, R.V.S., 2012. Análise do comportamento atmosférico em situação de seca: Uma abordagem operacional para Pernambuco. Revista Brasileira de Geografia Física, 04, 937-950.

Souza, W.M., Azevedo, P.V., 2009. Avaliação de tendências das temperaturas em recife-pe: mudanças climáticas ou variabilidade? Engenharia Ambiental, 6, 462-472.

Souza, W.M., Azevedo, P.V., 2012. Índice de detecção de mudanças climáticas derivados da precipitação pluviométrica e das temperaturas em Recife-PE. Revista Brasileira de Geografia Física. 1, 143-159.

Souza, W.M., Azevedo, P.V., Araújo, L.E., 2012. Classificação da precipitação diária e impactos decorrentes dos desastres associados às chuvas 
na cidade do Recife-PE. Revista Brasileira de Geografia Física, 2, 250-268.

Torres, R.R.; Ferreira, N.J., 2011. Case studies of easterly wave disturbances over Northeast Brazil using the eta model. Weather and forecasting, 26, 225-235.
Wanderley, L.S.A. Nóbrega, R.S., Moreira, A.B., Anjos, R.S., Almeida, C.A.P., 2018. As chuvas na cidade do Recife: uma climatologia de extremos. Revista Brasileira de Climatologia. 22, 149-164. 